\title{
Overcoming Glucosinolate-Myrosinase-Isothiocyanate Defense System by Plant Pathogenic Fungi
}

\author{
Fatemeh Rahimi (D) ${ }^{*}$, Siamak Rahmanpour ${ }^{(i) 2}$
}

${ }^{1}$ Department of Agriculture, Agriculture Services Center, Kalaleh, Golestan Province, Iran
${ }^{2}$ Seed and Plant Improvement Research Institue, Agriculture Research, Education and Extension Organization,
Karaj, Iran

Abstract: Natural compounds play an important role in shaping living plant responses. The resistance of plants is dependent on the formation and production of antimicrobial compounds of secondary metabolites. Glucosinolates (GSLs) are the main source of phytoanticipin in Brassicaceae and other plant families. The biological activity of glucosinolates are dependent on the release of various toxic compounds due to hydrolysis by myrosinase, isothiocyanate (ITC) is glucosinolate-breakdown products that inhibit the growth of microorganisms. In this review, we aim to understand how fungal pathogens overcome the glucosinolate-myrosinaseisothiocyanate system. The pathogens overwhelm the plant's defense system in various ways and disable each component of the system. Many plant pathogens may not cause tissue damage or activation of the glucosinolatemyrosinase-isothiocyanate system, others degrade or transforms the intact GSLs to less or non-toxic products, or inhibit the hydrolysis of GSLs catalyzed by myrosinase, or formed special mechanisms to detoxify toxic GSLs degradation products.

\section{ARTICLE HISTORY}

Received: September 04, 2019

Revised: December 09, 2019

Accepted: January 11, 2020

\section{KEYWORDS}

Secondary metabolite,

Glucosinolate,

Myrosinase,

Isothiocyanate

\section{INTRODUCTION}

Plants are exposed to environmental hazards such as herbivores and pathogens throughout their lives. Mechanisms of defense in plants help them to run from exterior attacks [1]. Selection pressure exerted by microorganisms and insects shapes the diversity of plant secondary metabolites [2]. In a position that is full of stress, plants can remember the situation and keep up themselves and their families toward aggressions of the future [3].

Natural plant products have an essential function in forming biological interactions [4]. Plant secondary metabolites promote communications with a diversity of detrimental and beneficial organisms [5]. Chemical defenses include the toxic, antinutritive, antimicrobial, antioxidant and anti digestive act of low-molecular-weight (LMW) compounds, such as alkaloids, phenolic and terpenoid compounds. The LMW compounds that have negative effects on pathogens and are synthesized exclusively during host-pathogen interactions are called phytoalexins, as the LMW compounds in plant tissue being are mentioned as phytoanticipins

CONTACT: Fatemeh Rahimi $₫$ faterahimi@gmail.com $\equiv$ Department of Agriculture, Agriculture Services Center, Kalaleh, Golestan Province, Iran 
[6]. The term phytoanticipin for glucosinolates and other similar compounds has been offered by Van Etten in 1994 to distinguish them from phytoalexins, which are produced after infection by pathogens. They have emphasized differences in the production procedure of these groups of plant secondary metabolites rather than their chemical structures [7].

\subsection{In Which Families, Gsl's Are Present?}

Phylogenetic analysis of the based on maximum parsimony sequences reveals two separate lineages of plants that produce glucosides. The main clade encompasses the core Capparalean families of Caricaceae, Resedaceae, Bataceae, Salvadoraceae, Capparidaceae, Gyrostemonaceae, Moringaceae, Limnanthaceae, Pentadiplandraceae, Tovariaceae, Koeberliniaceae, Brassicaceae, Akaniaceae, Cleomaceae, Emblingiaceae, Tropaeolaceae and Setchellanthaceae, and second lineage consists of the genus Drypetes, placed in Euphorbiaceae $[8,9]$.

\subsection{Glucosinolates Structural Diversity and Chemistry}

Glucosinolates are $\beta$-thioglucoside N-hydroxysulfates (too identified as (Z)-(or cis)-Nhydroximinosulfate esters or S-glucopyranosyl thiohydroximates), and a side chain (R) with a sulfur-linked $\beta$-D-glucopyranose moiety [10]. Sidechains of the glucosinolates are represented with broad chemical structures. A lot of the glucosinolates including branched or carbon straight chains. Most of the compounds comprising hydroxyl, groups of carbonyl, olefins (double bonds), or sulfur linkages in states of various oxidation. The greatest single group carries an atom of sulfur in different oxidation states [10].

Glucosinolates can be classified formed on the structure of several precursors of amino acid within three classes:

(i). Aliphatic glucosinolates constitute about 50\% of the known structures [11] and are obtained of methionine, isoleucine (AUC, AUU, AUA), leucine (CUG, CUC, CUA, CUU) or valine (GUC, GUU, GUG, GUA),

(ii). Benzyl glucosinolates $10 \%$ derived (Figure 1) from phenylalanine (UUU, UUC) or tyrosine (UAU, UAC),

(iii). Indole glucosinolates 10\% [11] and are obtained from tryptophan (UGG) [10], Indole glucosinolates division products vary from others on the change of the primary made by isothiocyanates at neutral or a bit acidic $\mathrm{pH}$ resulting in ascorbic acid expends, oligomeric blend and indole-methanols [12].

From other amino acids or their biosynthesis origin other $30 \%$ of structures are coming [11]. In each main group, a further variation of structural is getting by oxidation, hydroxylation or elongation of the side chain $[13,11]$.

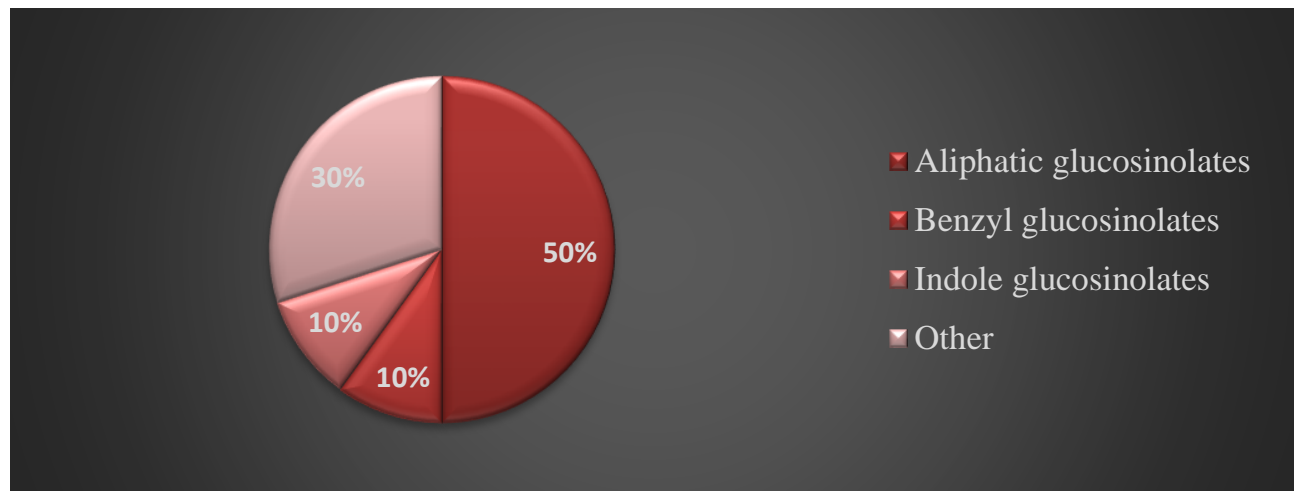

Figure 1. Classification of the percentage of known glucosinolates [11] 


\subsection{Glucosinolates Structural Diversity and Chemistry}

Glucosinolates attain their main biological activities by myrosinase hydrolysis (EC 3.2.3.1) and acts of related myrosinase-associated proteins such as epithio nitrile specifier protein (ESP), nitrile-specifier protein (NSP) and thiocyanates forming proteins (TFP) [5, 14]. Accessibility of presence of myrosinase-interacting proteins, ferrous ions and $\mathrm{pH}$ control the final mix that consists of epithionitriles, isothiocyanates, nitriles, oxazolidine-2-thiones and thiocyanates [15].

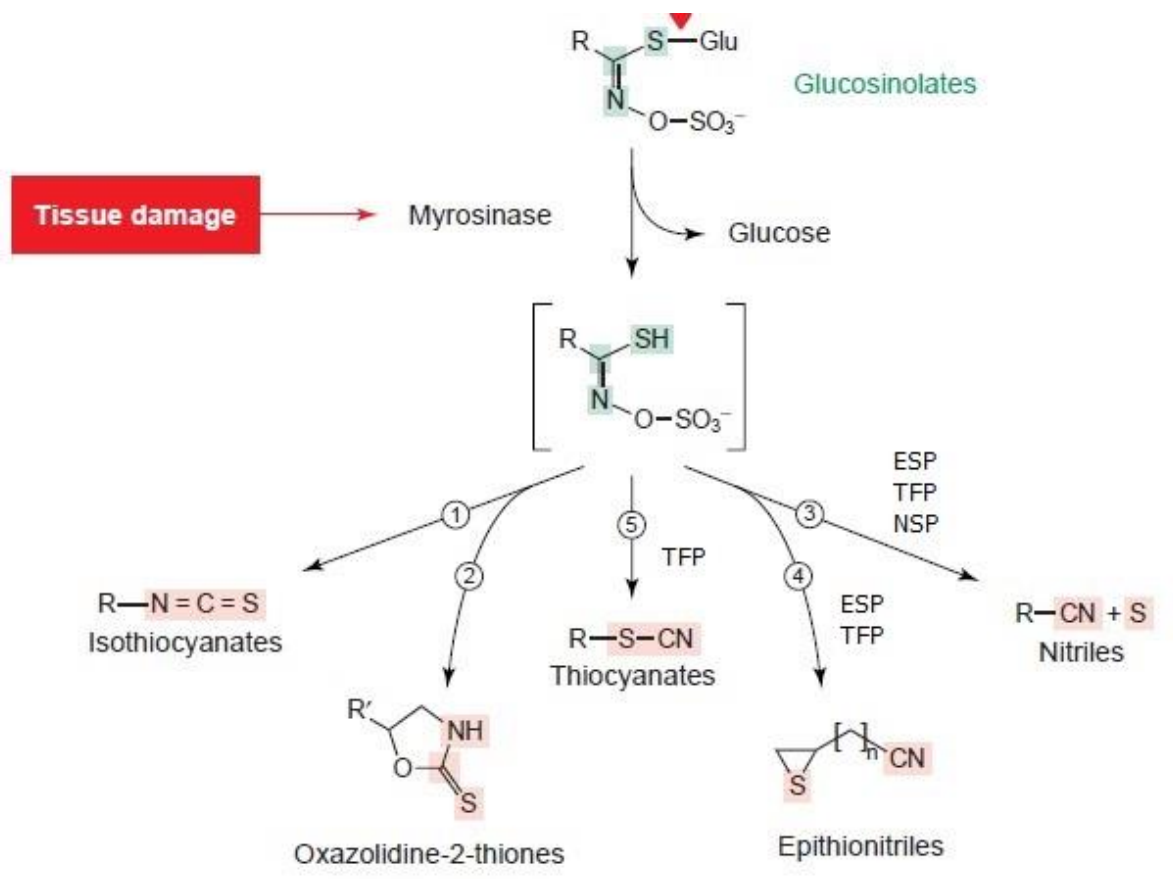

Figure 2. Glucosinolates hydrolysis [16]

\subsection{The Nature of Hydrolysis Products}

After hydrolysis of glucosinolates with myrosinases (Figure 2): At $\mathrm{pH}$ 5.0-7.0, isothiocyanates forms from an unstable aglucones $[16,17,18]$. Isothiocyanates take form in the absence of epithiospecifier protein (ESP) [17]. If the side chain of the glucosinolates is hydroxylated at carbon 3, isothiocyanate cyclization leads to the production of variable oxazolidine-2-thione [16, 18, 19]. In the presence of ESP, TFP and NSP proteins [20], the formation of nitrile has been proved in few states to be favored at down $\mathrm{pH}$, acidic $\mathrm{pH} 2.0-5.0$ and in the presence of $\mathrm{Fe}^{2+}$ ions, nitriles are formed [21]. If in the side chain there is a double final bond, the atom of sulfur issued as the production of nitrile and caught by the double bond, thus forming epithionitriles [22], epithionitriles and nitriles are made by the ESP and TFP proteins from alkenyl or alkyl glucosinolates [17]. Some glucosinolates can be hydrolyzed to thiocyanates [21]. Thiocyanates are only made of allyl, benzyl, and 4-methyl sulfinyl butyl glucosinolates [22]. Thiocyanate forming a TFP protein has been proved to be associated with this production [23].

\subsection{Myrosinase Enzyme}

In Brassicaceae and other 16 families of plant activity of dimeric myrosinase protein is available and by a group of iso-enzymes carried out. Enzymes characterized and purified are highly glycosylated and varied degrees activation of ascorbic acid [24]. The myrosinases have been found in bacteria, fungi and mammalian tissues. Myrosinase enzyme distribution is species and organ-specific [25]. The substrate specificity modified with epithiospecifier protein 
(ESP), myrosinase-binding protein (MBP), a myrosinase-binding protein-related protein (MBPRP) and myrosinase associated proteins (MyAP) [25].

\subsection{Roots Tissue Distribution of The Glucosinolate-Myrosinase-Isothiocyanate System}

The importance of glucosinolates act in plants is responses to environmental or external stimulation [8]. Glucosinolates and myrosinase are localized in various cells (Figure 3). Glucosinolates and ESP concentrate on various subcellular compartments a nuclear and cytoplasmic localize for ESP vacuolar localization. Types of cells are shown in the picture: (E) are epidermal cells expressing ESP; cellular colocalization indicates S-cells of ESP and glucosinolates; (M) are myrosinase-expressing phloem cells and guard cells; (S) are S-cells containing glucosinolates [20]. Cryo-scanning Electron Microscope (SEM) displayed in two layers, the cell under the outermost of the roots layer with secondary growth were found that have the most concentrations of glucosinolates. The initial tissue Cells had trivial glucosinolate rates. Myrosinase was restricted to secondary phloem and inner pericycle. Rhizosphere's glucosinolates released to the roots develop laterally. Myrosinase hydrolysis spreads in the root peripheral cell layers of the rhizosphere. The greatest role in these plants is the security of big roots during the important seed filling phases when roots as pipelines acting for water and nutrients [26].

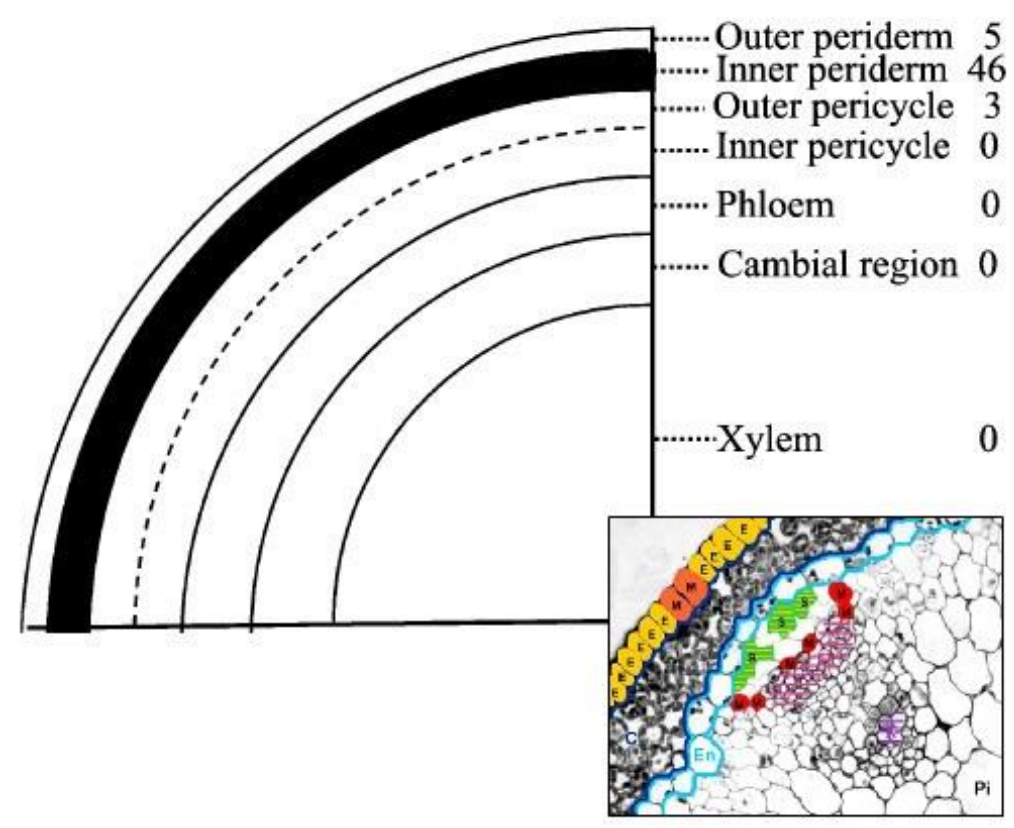

Figure 3. Left: Cross-section of a Brassica root at initial flowering stages. Numbers indicate glucosinolates concentration (mM) [23] Right: glucosinolates and myrosinase localization in various cells (C: cortex; En: endodermis; P: phloem; X: xylem; Pi: pith) [20]

\subsection{Overcoming to The Glucosinolate-Myrosinase-Isothiocyanate System}

Various glucosinolates hydrolysis products have different results on many pathogens. When glucosinolates are released from plants to the soil, they have important implications for the society of the rhizosphere. The predominant species of fungal nearby Brassicaceae containing glucosinolates in the soil are various than the predominant species of fungi that are found elsewhere and shows enhance endurance to ITC [27]. The first action of pathogens to the glucosinolate-myrosinase-isothiocyanate system is preventing exposure of toxic yield. Many plant pathogens may not cause tissue damage or activation of the GSL-M-ITC system. The MAM1 mutant of Arabidopsis, that has a few amounts of 4-methylsulfinlybutyl GSLs rather than the wild-type, is susceptible to Fusarium oxysporium but isn't to other bacterial and fungal 
species [28]. The release of a series of potentially toxic products upon the hydrolysis of GSLs by myrosinase enzyme had led researchers to propose that in the plant the GSL-M-ITC system has a nonspecific role as a system of plant defense [29]. The mechanism of ITC's biocidal activity against fungal pathogens is not yet known. But, two kinds of toxic effects have been noticed: direct and indirect toxic effects. In the direct effect, ITCs communicates with nonspecific and non-reversible proteins (and enzymes) [15]. Therefore, ITCs might easily inactivate enzymes [30], and the indirect effect of ITCs on exposed plant cells is GSLs hydrolysis products may interfere with plant defense signaling in particular systemic acquired resistance [31]. The compartmentalization of myrosinases and glucosinolates in different cells and tissues of the plant propose that for fungal pathogens, there are three possible ways to dominate the GSL-M-ITC defense system of hosts [32]:

Firstly, pathogen degrades or transforms intact GSLs to less-toxic or non-toxic products:

Phoma lingam and Verticillium dahliae can reduce some glucosinolates. The fungus degrades or deforms primary glucosinolates to compounds that are less or not at all toxic to prevent the production of glucosinolates degradation products by plant myrosinase. To improve the attempts of the plant resistance, both avirulent and virulent of $P$. lingam isolates could decline glucosinolates and the ability of glucosinolates to degrading fungal pathogens is an essential factor otherwise a determinant in pathogenesis [32]. Arabidopsis with levels of original GSLs and CYP79 genes show resistance to disease. GSLs compounds from decomposition aromatic GSLs raised to defenses of salicylic acid interfered so long as overcoming jasmine acid defense, as shown in improving sensitivity to Alternaria brassicicola [33]. The mechanism that used ITCs a specialist Brassica pathogen to cause cell death, exposure of the fungus Alternaria brassicicola to ITCs activated mitochondrial membrane depolarization, accumulation of intracellular reactive oxygen species (ROS) and reduced oxygen consumption rate [34].

Secondly, pathogens release during the pathogenesis special products, that inhibit the hydrolysis of glucosinolates catalyzed by myrosinase:

Some species of insects pass myrosinase hydrolysis with accumulating intact glucosinolates and veer glucosinolates hydrolysis [35]. Several of these insects use the GSLM-ITC system and their myrosinase for their defense $[17,36]$. The role of glutathione Stransferase enzyme (GST) in detoxifying the products of the GSL-M-ITC system in brassicas is a possible way for Sclerotinia sclerotiorum to disarm the plant performed defense system [37]. A brassica specialist insect, Plutella xylostella, diamondback moth, (Lepidoptera: Plutellidae), disarmed GSL-M-ITC system with GSL sulfatase (GSLS). This enzyme highly prevents toxic product formation of the GSL-M-ITC system, the enzyme can act on all major GSL classes indicating the ability of an insect to use a lot of Brassica plants. GSLS composition with host plant myrosinase has been observed for GSL substrate. Myrosinases could not use desulfo glucosinolates as a substrate and so GSLS disarms the GSL-M-ITC system within two direct and indirect ways, firstly by substrate removing the myrosinases, GSLs and secondly by its activity reducing by sulfate release [38].

Thirdly, pathogens have formed a special mechanism to detoxify toxic glucosinolates degradation products:

Pieris rapae, specialist lepidopteran, reduce the toxicity of the glucosinolates [39]. Pieris uses the enzyme of nitrile specifying protein (NSP) to the nitrile formation instead of isothiocyanates. ESP and NSP have related activities, but they do not have consistent sequences [40, 41]. Some tritrophic defenses are controlled by NSP interfered production of nitrile [17]. Interactions between Brassica and Leptosphaeria maculans, the blackleg fungal agent, can be discussed as a passive mechanism of reaction to the GSL-M-ITC system in Brassica plants. 
One resistance $B$. napus and one susceptible cultivar $B$. juncea have been used with the even histological diffusion, expression of isoform and enzymes of myrosinase activity and also similar levels of GSL to investigate the interactions of L. maculans and the host plants. On tissues of plant germination of the pathogen did not change GSL's and suggested that $L$. maculans does not degrade the GSL compounds. GSL-M-ITC system was not activated during infection [29, 42]. The pathogen may detoxify the GSLs hydrolysis products or particularly ITCs by other methods (the breakdown of antimicrobial volatiles) [42], similar to the detoxification of structurally related Brassica phytoalexins by $S$. sclerotiorum [43]. Mechanisms to evade the toxic effects of ITCs. For instance, brassica phytoalexins can be converted into less toxic compounds by L. maculans [42]. Pathogens and pests of brassica plants would actively react to the GSL-M-ITC system for two types of aims: a) pathological or nutritional purposes (Sulfur and nitrogen in glucosinolate reach the nutritional consumption of plant cells.), or b) neutralizing (detoxifying) purposes [42, 44]. Different activities determined for ITCs. The results obtained from the study explain the ability of Sclerotinia to adapt during the invasion of oilseed rape tissues. Despite the release of volatiles from infected leaf tissues, the pathogen could easily colonize them. The mechanism by which S. sclerotiorum could adapt to the toxicity of ITCs, in particular, is not known. Meanwhile, some hypotheses might be consistent with the pathogen reaction behavior [45]. Changes in the fungal cell membrane to neutralize ITCs water-oil partition coefficients (a measure of molecular lipophilicity or hydrophobicity), thus reducing uptake [46]. Glutathione S-transferases have been related in resistance to ITCs in fungi [47] and in Myzus persicae aphid in the adaptation to plant secondary metabolites, on feeding, Arabidopsis supply defense by transformed indole glucosinolate to other compounds $[48,49]$.

\section{CONCLUSION}

In plants living life, it has taken millions of years for glucosinolate-myrosinase-system to form. Pathogens reached a level of evolution that recognizes destroying any component of the system that can disintegrate and release the poison. This is a very precise and specific tactic, each with its way of controlling it. Volatile compounds are one of the earliest methods for combating plant hazards. Glucosinolates as a protector in the outermost part of the plant provide an independent defense mechanism that acts against pathogenic infiltration. Glucosinolates research enable us to more fully exploit the bio-potential of these compounds in medicine and agriculture. The identification of glucosinolates permits the engineering of glucosinolates metabolic to increase the practical to the imminent phase.

\section{Declaration of Conflicting Interests and Ethics}

The authors declare no conflict of interest. This research study complies with research publishing ethics. The scientific and legal responsibility for manuscripts published in IJSM belongs to the author(s).

\section{Orcid}

Fatemeh Rahimi (iD https://orcid.org/0000-0002-7567-6780

Siamak Rahmanpour (D) https://orcid.org/0000-0002-1072-2416

\section{REFERENCES}

[1]. Turner, J.G., Ellis, C., Devoto A. (2002). The jasmonate signal pathway. Am Soc Plant Biolthe Plant Cell., 14(1). https://doi.org/10.1105/tpc.000679

[2]. Bednarek, P., Bednarek, M., Svatos, A., Schneider, B., Doubsky, J., Mansurova, M., Humphry, M., Consonni, Ch., Panstruga, R., Sanchez-Vallet, A., Molina, A., SchulzeLefert, P. (2009). A glucosinolate metabolism pathway in living plant cells mediates broad- 
spectrum antifungal defense. Science, 323(5910),101-106. https://doi.org/10.1126/science .1163732

[3]. Pastor, V., Luna E., Mauch-Mani, B., Ton, J., Flores, V. (2013). Primed plants to do not forget. Environ Exp. Bot., 94, 46-56. https://doi.org/10.1016/j.envexpbot.2012.02.013

[4]. Kliebenstein, D.J. (2004). Secondary metabolites and plant/environment interactions: a view through Arabidopsis thaliana tinged glasses. Plant, Cell and Environment, 27(6), 675-684. https://doi.org/10.1111/j.1365-3040.2004.01180.x

[5]. Stotz, H.U., Sawada, Y., Shimada, Y. (2011). Role of camalexin, indole glucosinolatederived isothiocyanates in defense of Arabidopsis against Sclerotinia sclerotiorum. Plant Journal, 67(1), 81-93. https://doi.org/10.1111/j.1365-313X.2011.04578.X

[6]. Kovalchuk, A., Kerio, S., Oghenekaro, A.O., Jaber, E., Raffaello, T., Asiegbu, F.O. (2013). Antimicrobial defenses and resistance in forest trees: challenges and perspectives in a genomic era. Annu Rev Phytopathol, 51, 221-244. https://doi.org/10.1146/annurev-phyto082712-102307

[7]. Van Etten, H.D., Mansfield, J.W., Bailey, J.A., Farmer, E.E. (1994). Two classes of plant antibiotics: phytoalexins versus phytoanticipins. Plant Cell, 6(9), 1191-1192. https://dx.d oi.org/10.1105\%2Ftpc.6.9.1191

[8]. Merillon, J.M., Ramawat, K.G. (2017). Advances in botanical research: Glucosinolates. Springer International Publishing, Switzerland, pp. 473.

[9]. Rodman, J.E., Karol, K.G., Price, R.A. Systema, K.J. (1996). Molecules morphology, and Dahlgren's expanded order Capparales. Systematic Botany, 21(3), 289-307. https://doi.org /10.2307/2419660

[10]. Fahey, J.W., Zalcmann, A.T., Talalay, P. (2001). The chemical diversity and distribution of glucosinolates and isothiocyanates among plants. Phytochemistry, 56(1), 5-51. https://doi.org/10.1016/S0031-9422(00)00316-2

[11]. Hopkins, R.J., Van Dam, N.M., Van Loon, J.A. (2009). Role of glucosinolates in insectplant relationships and multitrophic interactions. Annual Review of Phytopathology, 54, 57-83. https://doi.org/10.1146/annurev.ento.54.110807.090623

[12]. Agerbırk, N., Olsen, S. (1998). Initial, and final products, nitriles, and ascorbates produced in myrosinase-catalyzed hydrolysis of indole glucosinolates. J Agric Food Chem, 46(4), 1563-1571. https://doi.org/10.1021/jf9708498

[13]. Grubb, D., Abel, S. (2006). Glucosinolate metabolism and its control. Trends in Plant Science, 11(2), 89-100. https://doi.org/10.1016/j.tplants.2005.12.006

[14]. Bones, A.M., Rossiter, J.T. (1996). The myrosinase-glucosinolate system its organization and biochemistry. Physiologia Plantarum, 97(1), 194-208. https://doi.org/10.1111/j.13993054.1996.tb00497.x

[15]. Brown, P.D., Morra, M.J., (1996). Hydrolysis products of glucosinolates in Brassica napus tissues as inhibitors of seed germination. Plant and Soil, 181(2), 307-316. https://doi.org/10.1007/BF00012065

[16]. Wittstock, U., Halkier, B.A. (2002). Glucosinolate research in the Arabidopsis era. Trends in Plant Science., 7(6), 263-270. https://doi.org/10.1016/S1360-1385(02)02273-2

[17]. Halkier, B.A., Gerchenzon, J. (2006). Biology and biochemistry of glucosinolates. Annu Rev Plant Biol., 57, 303-333. https://doi.org/10.1146/annurev.arplant.57.032905.105228

[18]. Redovnikovic, I.R., Glivetic, T., Vorkapic-Furac, J. (2008). Glucosinolates and their potential role in the ant. Periodicumbiologorum., 110(4), 297-309.

[19]. Kliebenstein, D.J., Kroymann, J., Thomas, M.O. (2005). The glucosinolate-myrosinase system in an ecological and evolutionary context. Curr Opin Plant Biol., 8(3), 264-271. https://doi.org/10.1016/j.pbi.2005.03.002 
[20]. Kolm, R.H., Danielson, U.H., Zhang, Y., Talalay, P., Mannervik, B. (1995). Isothiocyanates as substrates for human glutathione transferases: structure-activity studies. Biochemistry Journal, 31 1(2), 453-459. https://doi.org/10.1042/bj3110453

[21]. Uda, Y., Kurata, T., Arakawa, N. (1986). Effects of $\mathrm{pH}$ and ferrous ion on the degradation of glucosinolates by myrosinase. Agr Bio Chem, 50(11), 27352740. https://doi.org/10.127 1/bbb1961.50.2735

[22]. Hasap1s, X., MacLeod, A.J. (1982). Benzylglucosinolate degradation in heat-treated Lepidium sativum seeds and detection of a thiocyanate- forming factor. Phytochemistry, 21(5), 1009-1013. https://doi.org/10.1016/S0031-9422(00)82405-X

[23]. Burow, M., Bergner, A., Gershenzon, J., Wittstock, U. (2007). Glucosinolate Hydrolysis in Lepidium sativum Identification of the Thiocyanate-Forming Protein. Plant Mol Biol., 63(1), 49-61. https://doi.org/10.1007/s11103-006-9071-5

[24]. Thangstad, O.P., Winge, P., Husebye, H., Bones, A. (1993). The myrosinase gene family in Brassicaceae. Plant Mol Biol., 23(3), 511-524. https://doi.org/10.1007/BF00019299

[25]. Rask, L., Anderson, E., Ekbom, B., Eriksson, S., Pontoppidan, B., Meijer, J. (2000). Myrosinase: gene family evolution and herbivore defense in Brassicaceae. Plant Mol Biol, 42(1), 93-113. https://doi.org/10.1023/A:1006380021658

[26]. Mccully, M., Miller, C., Sprague, S. (2008). The distribution of glucosinolates and sulfurrich cells in roots of field-grown canola Brassica napus. New. Phytol., 180(1), 193-205. https://doi.org/10.1111/j.1469-8137.2008.02520.x

[27]. Ishimoto, H., Fukushi, Y., Yoshida, T., Tahara, S. (2000). Rhizopus and Fusarium are selected as dominant fungal genera in rhizospheres of Brassicaceae. J Chem Ecol., 26(10), 2387-2399. https://doi.org/10.1023/A:1005583012561

[28]. Tierens, K., Thomma, B.P.H., Brouwer, M., Schmidt, J., Kistner, K., Porzel, A., MauchMani, B., Cammue, B.P.A., Broekaert, W.F. (2001). Study of the role of antimicrobial glucosinolate-derived isothiocyanates in resistance of Arabidopsis to microbial pathogens. Plant Physiol, 125(4), 1688-1699. https://doi.org/10.1104/pp.125.4.1688

[29]. Mithen, R.F., Lewis, BG., Fenwick, G.R. (1986). In vitro activity of glucosinolates and their products against Leptosphaeria maculans. Transactions of the British Mycological Society, 87(3), 433-440. https://doi.org/10.1016/S0007-1536(86)80219-4

[30]. Kawakishi, S., Kaneko, T. (1985). Interaction of oxidized glutathione with allyl isothiocyanate. Phytochemistry, 24(4), 715-718. https://doi.org/10.1016/S0031-9422(00)8 4882-7

[31]. Kliebenstein, D.J., Figuth, A. and Mitchell-Olds, T., (2002). Genetic architecture of plastic methyl jasmonate responses in Arabidopsis thaliana. Genetics, 161(4), 1685-1696

[32]. Wu, X., Meijer, M.J. (1999.) In Vitro Degradation of intact glucosinolates by phytopathogenic fungi of Brassica. Proceedings of the $10^{\text {th }}$ International Rapeseed Congress, Canberra, Australia.

[33]. Brader, G., Mikkelsen, M.D., Halkier, B.A., TapioPalva, E. (2006). Altering glucosinolate profiles modulates disease resistance in plants. The Plant Journal, 46(5), 758-767. https://doi.org/10.1111/j.1365-313X.2006.02743.x

[34]. Calmes, B., Guyen, G., Dumur, J., Brisach, C.A., Campio, C., Iacomi, B., Pigne, S., Dias, E., Macherel, D., Guillemette, T., Simoneau, P. (2015). Glucosinolate-derived isothiocyanates impact mitochondrial function in fungal cells and elicit an oxidative stress response necessary for growth recovery. Frontiers in the plant. Science, (6), Article 414. https://doi.org/10.3389/fpls.2015.00414

[35]. Mueller, C., Agerbirk, N., Olsen, C.E., Boeve, J.L., Schaffner, U., Brakefield, P.M. (2001). Sequestration of host plant glucosinolates in the defensive hemolymph of the sawfly 
Athaliarosae. J Chem Ecol., 27(12), 2505 2516. https://doi.org/10.1023/A:101363161614 1

[36]. Jones, A.M.E., Winge, P., Bones, A.M., Cole, R., Rossiter, J.T. (2002). Characterization and evolution of a myrosinase from the cabbage aphid Brevicoryne brassicae. Insect Biochem Mol Biol, 32(3), 275-284. https://doi.org/10.1016/s0965-1748(01)00088-1

[37]. Seifbarghi, S., Borhan, M. H., Wei, Y., Coutu, C., Robinson, S. J., \& Hegedus, D. D. (2017). Changes in the Sclerotinia sclerotiorum transcriptome during infection of Brassica napus. BMC Genomic, 18(1), 266. https://doi.org/10.1186/s12864-017-3642-5

[38]. Ratzka, A., Vogel, H., Kliebenstein, D.J., Mitchell-Olds, T., Kroymann, J. (2002). Disarming the mustard oil bomb. PNAS, 99(17), 11223-11228.

https://doi.org/10.1073/pnas.172112899

[39]. Wittstock, U., Agerbirk, N., Stauber, E.J., Olsen, C.E., Hippler, M., Mitchell-Olds, T., Gershenzon, J., Vogel, H. (2004). Successful herbivore attacks due to metabolic diversion of a plant chemical defense. Proc Natl Acad Sci USA, 101(14), 4859-4864. https://doi.or g/10.1073/pnas.0308007101

[40]. Agrawal, A.A., and Kurashige, N.S., (2003). A role for isothiocyanates in plant resistance against the specialist herbivore Pieris rapae.J Chem Ecol., 29(6), 1403-1415. https://doi.org/10.1023/A:1024265420375

[41]. Van Poecke, R.M., Posthumus, M.A., Dicke, M. (2001). Herbivore-induced volatile production by Arabidopsis thaliana leads to the attraction of the parasitoid Cotesia rubecula: chemical, behavioral, and gene-expression analysis. J Chem Ecol., 27(10), 19111928. https://doi.org/10.1023/A:1012213116515

[42]. Sexton, A.C., Kirkgaard, J.A., Howlett, B.J. (1999). Glucosinolates in Brassica juncea and resistance to Australian isolates of Leptosphaeria maculans, the blackleg fungus. Australian Plant Pathology, 28(2), 95-102. https://doi.org/10.1071/AP99017

[43]. Pedras, M.S.C., P. Ahianhonu, W.K., Hossain, M. (2004). Detoxification of the cruciferous phytoalexin brassinin in Sclerotinia sclerotiorum requires an inducible glucosyltransferase. Phytochemistry, 65(19), 2685-2694. https://doi.org/10.1016/j.phytoc hem.2004.08.033

[44]. Rabot, S., Guerin, C., Nugon-Baudon, L., Szylit, O. (1995). Glucosinolate degradation by bacterial strains isolated from a human intestinal microflora. Proc. ${ }^{\text {th }}$ Int. Rapeseed Congress, Cambridge. B, 26, 212-214.

[45]. Rahmanpour, S. (2008). Studies on the role of the glucosinolate-myrosinase system resistance of oilseed rape to Sclerotinia sclerotiorum, Ph.D. Thesis, University of New England, Australia.116 pp.

[46]. Manici, L. M., Lazzeri, L., Palmieri, S. (1997). In vitro fungitoxic activity of some glucosinolates and their enzyme-derived products toward plant pathogenic fungi. Journal of Agricultural and Food Chemistry, 45(7), 2768-2773. https://doi.org/10.1021/jf9608635

[47]. Sellam, A., P Poupard., -Simoneau, P. (2006). Molecular cloning ofAbGst1 encoding a glutathione transferase differentially expressed during exposure of Alternaria brassicicola to isothiocyanates. FEMS Microbiology Letters, 258, 241-249. https://doi.org/10.1111/j.1 574-6968.2006.00223.x

[48]. Francis, F., Vanhaelen, N., Haubruge, E. (2005). Glutathione S-transferases in the adaptation to plant secondary metabolites in the Myzus persicae aphid. Archives of Insect Biochemistry and Physiology, 58(3), 166-174. https://doi.org/10.1002/arch.20049

[49]. Kim, J.H., \& Jander, G., (2007). Myzus persicae (green peach aphid) feeding on Arabidopsis induces the formation of a deterrent indole glucosinolate. The Plant Journal, 49(6), 1008-1019. https://doi.org/10.1111/j.1365-313X.2006.03019.x 